\title{
Food Preferences Survey in African Americans and West Af- ricans: A Cultural Exploration of Agreement and Divergence in Attitudes in Food Environments and Food Responses
}

\author{
Catrina Johnson ${ }^{1,2 *}$, Robert Corruccini ${ }^{3}$, Daniel Becque ${ }^{4}$, Wanki Moon ${ }^{5}$, Kola Ajuwon ${ }^{6}$, and \\ David Lightfoot ${ }^{1,2}$
}

${ }^{1}$ Genomics Core Facility, Southern Illinois University Carbondale, IL 62901,USA; 2 Department of Plant, Soil \& Ag Systems, Southern Illinois University Carbondale, IL 62901, USA; ${ }^{3}$ Center for Health, Nutrition \& Biomedicine P.O. Box 1062, Park Forest, IL 60466, USA; ${ }^{4}$ Department of Anthropology, Southern Illinois University Carbondale, IL 62901, USA; ${ }^{5}$ Department of Kinesiology, Southern Illinois University Carbondale, IL 62901, USA; ${ }^{6}$ Department of Physiology, Southern Illinois University Carbondale, IL 62901, USA $;{ }^{7}$ Department of Agribusiness, Southern Illinois University Carbondale, IL 62901, USA; ${ }^{8}$ Department of Animal Sciences \& Nutrition, Purdue University-Elkhart, IN 49707, USA.

Received: January 16, 2019 / Accepted: December 14, 2019

\section{Abstract}

African Americans, currently over-represented among low SES groups, have been found to be among the most at risk groups for obesity and type 2 diabetes. Phenotypic expression, such as obesity, result from the combined effect of genetic inheritance and environmental influences. Environmental dynamics interact with individuals on micro, meso and ecto levels (Bronfrenbrenner, 1989), are diverse and cultural (Vygotsky, 1993) and are learned by individuals through modeling and observation (Bandura, 1989). Environmental factors such as parental influence and modeling, availability and accessibility of produce, sweetened drinks and fast foods, can contribute to or minimize the onset of obesity and type 2 diabetes. Consumption of fruits, vegetables and water has been shown to militate against the onset of obesity and type 2 diabetes. In the study 'Genetic Bottlenecks Impacting Genes Governing Food Responses in African Americans' the author considers the genetic and environmental responses to the onset of obesity and type 2 diabetes among African Americans. The author uses a culturally competent model for repeated traits $*(P=\mu+G+E p+E t)$ to evaluate the genotype/phenotype of African Americans. This model incorporates the contribution of temporary and permanent cultural environmental factors of historical origin, related to food responses, predisposition, metabolism and ethnic adjusted mean values of physical assessment to examine if the environment/genotype variables are informative towards the type 2 diabetes expression among African Americans, and to assess the validity of BMI as a predictor of adiposity and/or obesity prevalence among non-European populations. The main goal was to evaluate the relationship between BMI, fat distribution/prediction, variation among phenotypes and assess their relationships to the obesity genotype and environmental influences affecting metabolism and food choice. An independent study confirmed BMI to be an ineffective predictor of obesity in African and African American populations. There was found to be different correlates and determinants of BMI and diabetes in African and African Americans. Some aspects differed between American-born and African-born African Americans. Barriers existed on the level of community affecting African Americans. Changing U.S. food environment exposed African and African Americans to the obeseogenic effects of fast food, GMOs and growth hormones. Diabetes will continue to affect AA's in response to historical pressures of the past and additive pressures of subjugation pressure and poverty.

Keywords: African, African-Americans, SES, type 2 diabetes, environment, modeling, observation, parental influence, produce consumption, affordability.

\footnotetext{
"Corresponding author: johnsoncatrina@gmail.com
}

This is an Open Access article distributed under the terms of the Creative Commons Attribution License (http://creativecommons.org/licenses/by/3.0/), which permits unrestricted use, distribution, and reproduction in any medium, provided the original work is properly cited. 


\section{Introduction}

Man, is said to be a product of his/her environment. Similarly, man is a product of his/her food environment. Environment, the stage upon which genes act, is a dynamic that influences the phenotype, and consequently the genotype of all individuals, in complex ways, encompassing temporary and permanent affects and playing out on macro and micro levels. This study unpacks the dynamics of environment towards a revelations of food preferences for an African and African American cohort, across 131 variables and 20 categories that included: food availability and affordability, SES, parental modeling, proximity, and BMI.

Studies have shown there to be a direct association with income and food choice (Turrell et al., 2003). Healthy consumption of fruits and vegetables, low or nonfat milk and whole grains is a privileged behavior (Gregson, 2009). Affordability has been shown to present a barrier to fruit and vegetable consumption among low income households (Cassady et al., 2007). In order to reach national dietary benchmarks, low income households would have to spend as much as $70 \%$ of their income on fruits and vegetables (Cassady et al., 2007). The higher cost of whole grains and lean meats causes poor families to make poor food choices that are affordable and unhealthy (Jetter and Cassady, 2006). In general, low SES also causes high environmental stressors, increases cortisol levels in children and negatively impacts health and well-being (Lupien et al., 2000).

Feeding restriction and food control is the same among class regardless of income. Studies show that shared family meals gives parents a good chance to impact nutrition, produce consumption and prevent obesity causing factors like high fat/ sugar consumption and eating while watching T.V. (Utter et al., 2008). Parents can model a positive food environment for their children. Parental consumption of milk and produce influences that of their children (Arcan, 2007). Good nutrition among African American children can be influenced by observed eating habits of their parents (Tibbs et al., 2001). Observed produce consumption in parents and the child's food preferences, influences the produce intake of the that child (Wardle et al., 2005); (Nanney, 2007). Produce availability at mealtimes influence consumption in adolescents (Arcan, 2007). Children raised in households with authoritative styles (highly strict and highly involved) showed the most favorable consumption of fruits and vegetables (Kremers et al., 2003). "Experiences such as eating fresh-picked fruits and vegetables while growing up or vegetable gardening as an adult may enhance vegetable consumption among members of some ethnic groups" (Devine et al., 1999)."Households where produce consumption is encouraged and observed in parents impacts produce consumption in children favorably (Young, 2004).Homes with produce gardens have been shown to have increased produce availability (Nanney, 2007).

Parents can model a negative food environment in the home for their children that can set the stage for adult obesity. Fat intake in children is related to parental behaviors. Children who grow up in environments having parents who are high fat con- sumers are likely to model this behavior (Rossow, 1994).

Studies have shown that consumption of sweetened drinks from childhood to adulthood causes overweight in women (Nissinen et al., 2009). Parents have been shown to influence consumption of sweetened drinks in children (Van der Horst \& et al., 2007). The choice to breast feed or not to breast feed can also set the stage for adult obesity. Breast feeding prevents obesity in children. Lack of breast feeding among the poor leads to fat children (Martorell et al., 2001). And there are additive factors in childhood that will compound issues of future obesity. Fat cells formed in children during adolescence will stay the same during adulthood. A parent's failure to control a child's calories during the slow growth period leads to adult obesity (Spalding, 2008).

The food preparation/consumption environment of the home can also be obesogenic. Consumption of fried foods and low consumption of vegetables have been associated with obesity (BMI) in African Americans (Weinrich et al., 2007). Fried foods and lack of vegetable consumption have been associated with obesity in studies involving Black men (Weinrich et al., 2007).

Studies show that equidistance to agricultural products, like gardening, can positively influence fruit and vegetable consumption (Devine et al., 1999). Among Black youth produce consumption is influenced more by convenience than home availability (Befort, 2006). But there exists a problematic reality to consumption. There are separate but unequal food environments for Black and White, wealthy and poor (Gregson, 2009). Grocery stores with adequate produce supply are often out of reach for disadvantaged African Americans (Zenk et al., 2005). Only canned and frozen vegetables are available in neighborhoods that are all Black (Morland et al., 2007), thereby putting Blacks at risk for BPA exposure and its adverse effects on health. Local grocery stores with inadequate supplies of healthy foods contribute to a nutritionally poor food environment with regards to consumption of whole grains and lean meats (Jetter and Cassady, 2006). No health clubs or grocery stores with produce sections cause more obese neighborhoods. It is a function of wealth and race (Black, 2008).

Aside from parental/home influences, food preparation, availability, SES status and environmental estrogens that act upon the phenotype, proximity of fast food restaurants to residential areas increases the risk of community obesity. Equidistance to fast food outlets can have a negative nutritional impact because fat consumption is influenced by fast food visits (Befort $\mathrm{C}, 2006$ ). Obesity, high fat, low produce consumption and poor health is associated with fast food consumption among African Americans (Satia et al., 2004).

Proximity of produce markets to residential areas compared to fast food vendors has been shown to be an obesogen, or an environmental factor, shown to have a direct relationship to obesity among local populations (Spence \& et al., 2009). Structural inequality translates to local inequality of place and poverty has an effect on BMI (Gregson, 2009).

The school environment can play a role in student food choice and potentially impact the home/parent environment. Targeting student self efficacy could improve fruit and vegeta- 
ble consumption (Young, 2004). In urban populations, education and cultural upbringing can influence fruit and vegetable consumption (Devine et al., 1999)."Educators might focus on improving home fruit and vegetable availability, student self efficacy, as well as parent support and modeling. The level of availability might indicate where efforts should focus for enhancing parent behaviors (Young EM, 2004).”Educational programs promoting awareness of local produce sources and facilitating the development of garden programs may be a worthwhile investment (Nanney MS, 2007)."

On a macro level, the growth of fast food in our local and worldwide consumption environment is exacerbating obesity. Modernizing countries are experiencing obesity due to Americanized fast foods (Astrup A, 2008). There is a global variation of transfat levels among fast food chains (Stender \& et al., 2007). Abdominal obesity is related to transfat consumption of fast food (Astrup A, 2008). In general, large portion sizes, high trans fat levels and frequent consumption leads to obesity and related diseases worldwide (Stender et al., 2007).

On a micro level of ethnic-cultural environment, variation can be significant. There is cultural variation in obesity attributable to environment. The change from walking to driving in society has been shown to impact obesity in some ethnic groups. Increases in African American obesity, beginning in 1940 might be attributable to automobiles (Komlos et al., 2009).

\section{The Food Preferences Survey}

The Food Preferences Survey is a tool that was designed to understand where food preferences came from. Are they individual, learned, environmental or cultural? It also examined an individual's relationship to food in their environment and if this relationship is a contributing factor to obesity or leanness? The questions, by design, provide insight into what kinds of foods are in the participant's pantry, freezer, and refrigerator. How they prepare food and if they prepare foods like their parents did? The Survey looked at barriers to nutrition like affordability, socio-economic status, and availability due to factors like proximity of grocery stores. Was the individual raised and/or do they currently reside in a food desert where grocery stores containing fresh fruits vegetables and meats are more than 5 miles away? Overall 131 variables were included in questions asked that spanned across 20 categories of: affordability, availability, Body Mass Index, BPA (environmental estrogen) exposure, consumption, cultural influence, diabetes affected, education, exercise, food preferences, food preparation, gardening, geography, meal planning, meals w/ family, obesity, obesity prevention, parental facilitation, socio-economic status and time spent in the U.S.

The categories and variables represent a micro perspective that captures the actions of the actor. The Food Preferences Survey also pans out to include a macro perspective of the actor in their context of environment and challenges the observer to imagine how the particulars of environment could impact food choices and preferences? For instance, could rural, suburban or urban geography act upon food availability? Could the diets particular to tribe and culture impact consumption? What cul- tural norms may have impacted the parents and the maternal and paternal grandparents that could have been passed down to participant?

\section{Methods}

Environment, according to Vtgoksky (Vygotsky, 1993) is diverse and cultural. The participants included 3 groups in two categories: African American and their West African reference population. The African participants represent those who had been in the U.S. for 10 yrs or more and 10 yrs or less. The study concluded with a diverse African population that included a majority of West Africans. The greater Diaspora of African countries are reflected that capture West African cultures not just where they traditionally reside but cultures and generations in migration. The Survey captures the geography of not just the participants but their parents and maternal and paternal grandparents. In all, 16 countries are represented that include: Zimbabwe, Ethiopia, Zambia, Nigeria, Togo, Eritrea, Ghana, the Republic of Congo, Trinidad, Benin, Cote d Ivoire (Ivory Coast), Jamaica, Ireland, the European Union and the United States of America. The regions of West Africa, East Africa and South Africa are represented as well as the U.S. Southern, Northern, Central, Midwest and Eastern regions and rural, suburban and urban lifestyles. 24 African tribes are represented that include: Shona, Edo, Oromo, Akan, Urhobo, Tigrinya, Twi, Benin, Afro-Trinidad, Luba, Ijaw, Ibo, Ashanti, Etuno, Amhara, Yoruba, Kuric, Efik, Ewe, Tchokossi, Dominican, Zamunda, Puerto Rican, Lakota, Cherokee and African American. Eighteen languages were spoken among our participants and their parents in addition to English: Yoruba, Izon, Efik, Hausa, Edo, Benin, Ibo, Baoule/Agni, Ewe, Etuno, Urhobo, Benin, Oromo, Tigrinya, Amharic, Shona, French, Spanish and Patois.

Lineage. Self reported maternal and paternal lineage data was collected from participants include: age, tribe, birthplace and rural vs. city migratory origin. This data was used to establish participant's admixture status. This study required participants have both parents that are of African American, West African or Gullah origin.

Food Preferences. Participants were required to complete a survey that measures food preferences and produce availability and food preparation methods. Data was used to establish a potential point of origin for food preferences.

Food Journal. Participants were also required to fill out a 3 day journal recording food intake. Data was evaluated by a Registered Dietitian who will analyze the nutritive content of food intake.

\section{Results and Discussion}

\section{How The Responses Were Examined}

The responses in this survey were examined in terms of all group and individual responses. For instance, if a question was asked like: "Do you like meat?" If $67 \%$ of all participants asked says "yes" or "no", this percentage is discussed here as "the response of all groups." Next, the percentage of responses 
within each of the two groups of African or African American is discussed. The African group represented a combination of Africans who have been in the U.S. 10 yrs or more and ten yrs or less. Of the 76 total participants, the African group consisted of 43 individuals and the African-American group consisted of 33 U.S. born Blacks of slave descent, who had never been to Africa. The percentages of each groups' response were responses in reference to a part of the whole. For instance, all participants might respond "yes" or "no" to a particular question. Using the above stated example, if $67 \%$ of all responses said this or that, the group responses looked at what percentage of that $67 \%$ was African or African-American. If $20 \%$ of the total group response was African and $47 \%$ was African-American, the group response asked of the $20 \%$ who responded this way, what percentage of the response of all Africans would that represent. Using our example, $20 \%$ of total group response by African American could mean that $87 \%$ of everyone in that group comprised the response of "yes" or "no" to that particular question. The responses of both groups were then compared in terms of similarities and differences between the two groups and this was discussed and placed in context of the larger question of if food preferences are shared within a group of the same origin like African and African Americans-though separated by geography by hundreds of years?

The non-responses were not indicated where they occurred for the sake of simplicity.

\section{Affordability}

Fruit, vegetables and meat were affordable to Africans and African Americans. There were subgroups within each that couldn't afford these items (Table 1). The indication here was, that if meat were free, these groups would over consume this product, therefore, the removal of cost as a barrier to meat consumption may lead to overconsumption. Affordability of fruits and vegetables were correlated among Africans and African American groups and may pose a barrier to produce consumption (Nord, 2002; Alaimo, 2001). It is indicated that that affordability of meat was not a barrier and did not put these groups at risk for poor food choice with regard to meat.

\section{Availability}

Both groups had fruit, vegetables and meat in their kitchen in some form. What was problematic was that African-Americans derived their fruits and vegetables from cans and then from frozen (Table 1). This indicated that the participants were from neighborhoods where fresh fruit and vegetables are only available in canned and frozen forms. This was confirmed by Principal Component Analysis that showed a highly significant interaction between "vegetables in the pantry awaiting meal preparation" and," if there were vegetables in the freezer awaiting meal preparation $(\mathrm{P}=<.0001)$." There was a highly significant positive correlation with "if there were fruit in the refrigerator" and "if there were vegetables in the freezer $(\mathrm{P}=<.0001)$." The location of a grocery store within 2-5 miles of the participant was a highly significant interaction with, "if there were fruits in the refrigerator $(\mathrm{P}=<.0001)$." There was an interaction between" raw meat in the refrigerator awaiting meal preparation" and, "if there was raw meat in the freezer awaiting meal preparation $(\mathrm{P}=<.0001)$." There was a highly significant interaction between "if there were vegetables in the freezer" and "if there were vegetables in the pantry awaiting meal preparation $(\mathrm{P}=<.0001)$." And," if there was a fast food outlet where the participant lived' and "how many times they ate there," were also highly significant interactions $(\mathrm{P}=<.0001)$. These factors indicated that African Americans were under the effects of disadvantaged community (Black, 2008; Zenk et al., 2005; Moreland, 2007; Gregson, 2009), the effects of BPA (Poole, 2004; Hyoung et al., 2007) and spatial access to grocery stores or food deserts (Moreland, 2007; Zenk et al., 2005) and these barriers may have effects on the BMI of both groups (Spence et al., 2009; Ruel et al., 2010).

\section{BMI}

1. BMI falsely assumed the presence of fat. It was assumed that the resultant values for mass in this population correlated with fat (Table 1). It did not (Kok et al., 2004; Leading Toxicology Laboratories, 2015, 2017; Kennedy et al., 2009; Johnson, 2019).

2. BMI cutoffs were not found to be accurate across ethnicity (Evans et., 2006; Mills et al., 2007; Kok et al., 2004). According to the BMI standard, $48 \%$ of both of these groups would be classified as overweight and obese, with African Americans comprising $41 \%$ of this category and Africans comprising even more at $45 \%$. There was stern disagreement in the data that this population was $48 \%$ overweight and obese. When applied within the comparison of African Americans and their reference population-West Africans, in the within group comparison, showed their BMI value to be within normal range w/ $70 \%$ of body mass to be explained by fat free muscle compositionwhich is in agreement with the cultural standard for Africans and African American somatotype of mesomorphy, having a large component of body mass comprised of muscle mass (Heath and Carter). Therefore the BMI standard could not be used accurately to assess adiposity among all cultural groups, only within groups (Satija, 2016; Wagner and Heyward, 2000; Smalley et al., 1990; Johnson, 2019).

\section{Statistics}

Multiple Regression analysis using the fat free mass value of muscle weight in lbs as the dependent variable showed it to have a highly significant $(\mathrm{P}=<.0001)$ positive correlation with BMI. Muscle percentage had a highly significant $(\mathrm{P}=<.0001)$ positive correlation with BMI. The fat free mass value of bones, when used a dependent variable in Multiple Regression analysis had a highly significant $(\mathrm{P}=<.0001)$ positive correlation with BMI (Table 2).

Linear Regression analysis examining Bone Density $(\mathrm{Db})$ as a variable against BMI found it to be a highly significant $(\mathrm{P}=<.0001)$ positive correlation. Linear Regression analysis examining the interaction between BMI and Fat resulted in a 
highly significant $(\mathrm{P}=<.0001)$ positive correlation.

A Multiple Regression analysis examining the same interaction found it to be a significant positive correlation $(\mathrm{P}=.0060)$ (Kennedy et al., 2009; Smalley et al., 1990) (Table 2).

Principle Component Analysis (PCA) of the interaction of height and weight revealed that weight accounted for $54 \%$ of the variation in BMI among Africans and African Americans (Table 1).

\section{$B P A$}

Africans and African Americans were found to be of a generation that grew up in the U.S. under plastics and microwaving. Microwaving was a preferred method of cooking for African Americans vs. Africans. African Americans were found to derive almost all of their vegetables and fruits from cans and they liked vegetables heated from cans. African Americans were found to be in the low income group below $\$ 25,000$ where mean BPA concentrations were found to be the highest (Lang et al., 2008). Africans were found to be in a demographic age group between 18-25 yrs where mean BPA concentrations have been shown to be the highest (Lang et al., 2008). African Americans were found to be in the ethnic demographic group having the highest mean concentrations present in urine samples (Lang et al., 2008). Additionally, because African Americans weren’t breast fed as their African components were, they were found to have likely derived further exposure to BPA from plastic baby bottles as babies and formula (Union, 1999; Cao, 2008; Newbold et al., 2007) and may have been at risk of underdevelopment of their metabolic systems as babies (Janssen S. in Kotz, 2008). Therefore, African Americans were found to be at great risk for the effects of BPA which include obesity (Takeuchi et al., 2004; Lang et al., 2008) adverse effects in the brain, immune system and reproductive system (vom Saal and Hughes, 2005); heart disease (Newbold et al., 2007) ; increased disposition towards breast cancer, infertility and reproductive malfunction (Brotons, et al., 1995), adverse effects on cell function (Welshons et al., 2006); ovarian cyst disease in women (vom Saal, 2005) advanced sexual maturation (Howdeshell et al., 1999) and diabetes, per standard deviation of exposure (Lang et al., 2008).

\section{Consumption}

\section{Beverages}

With respect to beverages, Africans and African Americans were neutral in their preferences for milk and they deviated from their parent's preference for whole milk by preferring low fat milk; they both liked sweet tea, soda, Koolaid and water. Sweetened drinks were a part of the nutritional belief system of both African and African American parents and they facilitated consumption to their children accordingly. Africans liked the sweetened drinks more than their African American counterparts.

Female Africans and African Americans were found to be at risk for energy overweight in adulthood due to their exposure of consumption of sweetened drinks from childhood (Nissinen et al., 2009), with the risk among the African group to be greater. Both Africans and African Americans were found to be at risk for obesity and type 2 diabetes, due to exposure of high fructose corn syrup (HCFS) in soda (Goran et al., 2012). Both African and African American parents were found to possess poor nutritional beliefs with regards to feeding their children sweetened drinks (Anderson and Blackburn, 2008). Africans were found to be at risk for transition away from traditional diets towards Westernized eating habits and obesity and obesity related diseases, due to their consumption of sweetened drinks (Astrup, 2008).

\section{Fast Food}

Both groups liked to eat fast food and attributed their love of fast food to themselves. African Americans were more likely though to have exposure to fast foods in the region where they grew up and lived than Africans. The parents of African Americans raised them eating fast foods, while the parents of Africans raised their children on home cooked meals. More African American parents ate fast foods in front of their children, thereby modeling fat consumption, than African parents.

Both Africans and African Americans were at risk of fat consumption from fast food outlets (Befort, 2006); abdominal obesity due to trans fat consumption from fast foods (Astrup, 2008; Weinrich et al., 2007) and poor health from fast food consumption (Satia et al., 2004). African Americans were found to be at risk for the effects of disadvantaged community due to promixity and access to fast foods in their community, making their neighborhoods obesogenic, or an environmental factor shown to have a direct relationship to obesity among local populations (Spence et al., 2009). Africans were found to be at risk for transition away from traditional diets towards Westernized eating habits and obesity and obesity related diseases, due to their consumption of fast foods (Astrup, 2008).

Because their parents raised them eating fast foods, this was found to be in the nutritional belief system of African American parents (Anderson and Blackburn, 2008); African Americans were found to be at risk for acquisition of fat cells in childhood due to exposure of fast food; not being raised in calorie controlled environments in childhood and therefore gaining permanent fat cells in adulthood that contribute to the obese phenotype (Spalding, 2008). African Americans were found to be at risk for modeling high fat consumption before their children because their parents modeled this behavior toward them (Rossow, 1994).

\section{Fish, Fruit, Meat and Poultry}

Both groups liked to eat fish, fruit and meat. They both liked their vegetables steamed and had parents who modeled facilitated consumption of vegetables to them during dinner and lunch time. More African American parents facilitated vegetable consumption during dinner to their children than African and more African facilitated consumption of vegetables to their children during lunchtime than African American. Only African 
Table 1. FP Survey Category Tables PCA Analysis of Significant Interactions.

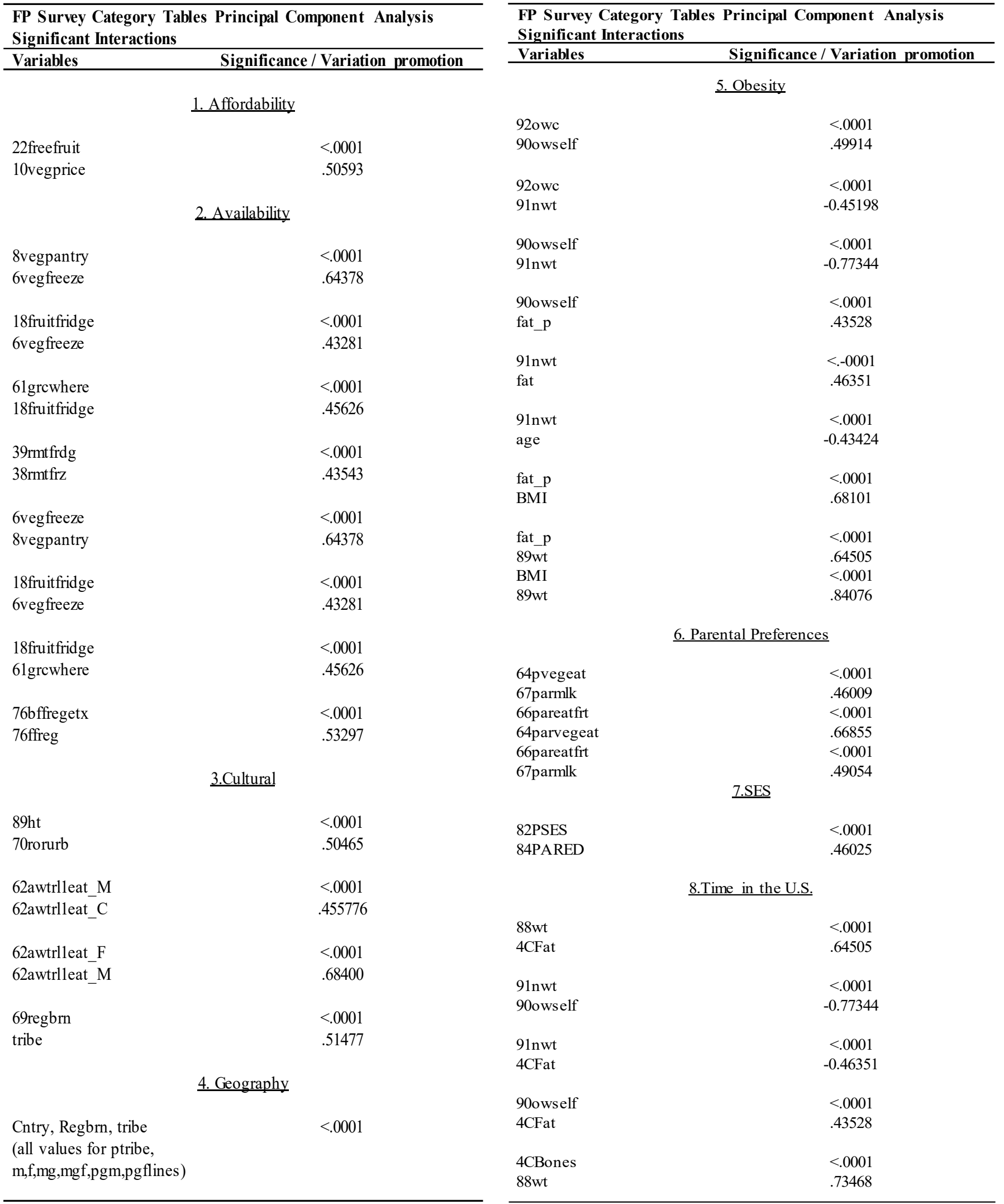


Table 2. FP Survey Significant Questions Multiple Regression (BF\%).

\begin{tabular}{|c|c|c|}
\hline \multicolumn{3}{|c|}{$\begin{array}{l}\text { FP Survey Significant Questions Multiple Regression } \\
\text { Dependent Variable }=\text { Body Fat } \%\end{array}$} \\
\hline [Code] / Questions & $\begin{array}{l}\text { Secondary } \\
\text { Variables }\end{array}$ & $\begin{array}{c}\mathbf{P} / \mathbf{F} \\
\text { Value }\end{array}$ \\
\hline 1. [brorbtl] & $\mathrm{N} / \mathrm{A}$ & $<.0001$ \\
\hline \multicolumn{3}{|l|}{ Were You Breast or Bottle Fed? } \\
\hline 2. [2friedfs] & $\mathrm{N} / \mathrm{A}$ & $<.0001$ \\
\hline \multicolumn{3}{|l|}{ Do you eat fried foods? } \\
\hline 3. $[2 \mathrm{a} 2 \mathrm{x}]$ & N/A & $<.0001$ \\
\hline \multicolumn{3}{|l|}{ How often (do you eat fried foods? } \\
\hline 4. [63fsitdown] & $\mathrm{N} / \mathrm{A}$ & $<.0001$ \\
\hline $\begin{array}{l}\text { Were you raised having family sit down meals? } \\
\text { 5. [920wc] }\end{array}$ & N/A & $<.0001$ \\
\hline \multicolumn{3}{|l|}{$\begin{array}{l}\text { If you describe yourself as overweight, were you } \\
\text { overweight as a child? }\end{array}$} \\
\hline 6. [26s odalike] & Weight & $<.0001$ \\
\hline Do you like soda? & $<.0001$ & \\
\hline 7. [26as odaxwk] & Weight & $<.0001$ \\
\hline If so, how often do you consume soda per week? & $<.0001$ & \\
\hline 8. [13tveat] & Weight & $<.0001$ \\
\hline Do you eat while watching t.v. & $<.0001$ & \\
\hline 9. [yrs] & Weight & $<.0001$ \\
\hline How long have you been in the U.S. & $<.0001$ & \\
\hline 10. [24 waterdrink] & Weight & $<.0001$ \\
\hline Do you drink water regularly? & $<.0001$ & \\
\hline 11. [1 ahowms wts ] & $\mathrm{N} / \mathrm{A}$ & .02804 \\
\hline \multicolumn{3}{|l|}{ Do you eat sweets more than 5 times a week? } \\
\hline 12. [57rsetgff] & Group \#1 & .0092 \\
\hline Were you raised eating fast foods? & $<.0001$ & \\
\hline
\end{tabular}

Americans preferred vegetables heated from a can, while their African counterparts were raised to and consumed vegetables from the garden. Both groups liked vegetables, ate on the run, liked sugar and ate while watching television.

African American preference for fried foods can put them at risk for obesity (Weinrich et al., 2007) and male prostate cancer development via the consumption of grilled red meat (Tang et al., 2007). Both Africans and especially African Americans were found to be susceptible to colon cancer, due to their heavy red meat consumption and preferences for well-done meat in particular, due to the tendency of overcooked red meat releasing enzymes that metabolizes carcinogens (Cotterchio et al., 2008). African American women may benefit from protection against colon cancer due to consumption of poultry (Tang et al., 2007; Cotterchio et al., 2008); Giovanni et al., 1994; Sharma, 2007). Africans were found to be at risk of obesity and related diseases due to their tendency to like their poultry and fish fried. Both African and African Americans were found to have parents who influenced vegetable consumption positively and influenced good nutrition in them (Nanney, 2007; Tibbs et al., 2001; Young, 2004; Anderson et al., 2009; Anderson and Blackburn, 2008; Kremers et al., 2003) that could result in their future consumption (Arcan, 2007). Both Africans and African Americans were found to be at risk for obesity and poor nutrition because they liked to eat on the run (Utter, 2008). Both Africans and African Americans were found to be at risk of obesity due to sugar consumption (Goran et al., 2012; Nissinen et al., 2009). Both
Africans and African Americans were found to be at risk of fat consumption influenced by television viewing (Befort, 2006). African Americans were found to be at risk for exposure to the obesogenic environmental estrogen Bisphenol A (BPA) due to their consumption of fruits and vegetables from cans (Brotons et al., 1995). African parents were found to facilitate the cultural upbringing of eating produce from the garden that may influence consumption in their children for garden produce in adulthood (Devine, 1999). African and African American parents were found to provide home cook meals, African parents did this more frequently than African Americans (Anderson and Blackburn, 2008).

\section{Cultural Influences}

African Americans were from Midwest and Africans were from West Africa. No parents in either group grew up or currently lived on a farm. African parents were from an urban setting, African American parents were from a rural setting. Participants in both groups were from urban settings. [The African American participants were primarily from the Midwest. This region has the distinction of being the bread basket to the world and though they are from Chicago, this metropolis is surrounded by a rural setting (Illinois is a prairie biome), therefore the participants responded "rural setting" vs. "urban"]. With regards to diets Africans had more of a tendency to be food restricted than African Americans, from pork. Principal Component Analysis 
(PCA) correlated the eight of participants with the fact of "if they were from rural or an urban setting $(\mathrm{P}=<.0001)$;" the "religious restriction of the consumption of meat" with "religious restriction of chicken $(\mathrm{P}=<.0001)$;" "religious restriction of the consumption of fish" was correlated with the "religious restriction of the consumption of meat $(\mathrm{P}=<.0001)$;" and the "region born" had a highly significant interaction with the "tribe" of participants $(\mathrm{P}=<.0001)$ (Table 1$)$.

\section{Diabetes Affected}

Principle Component Analysis examined the relationship between responses to the questions of "if type 2 diabetes ran in the participants families" and "if the participants themselves reported a diagnosis of type 2 diabetes." The diagnosis of type 2 diabetes among participants accounted for $52 \%$ of the variation of the Diabetes, Affected category (Table 1).

The majority of the participants did not report a diagnosis of type 2 diabetes, however there were two participants who did, both were African American. One was from the Caribbean West Indies and having a very remarkable family history with the disease (i.e. amputations, blindness) on her maternal side. The other was the oldest female in the study (48yrs old) who reported adult onset type 2 diabetes.

A regional pattern of fat distribution used to predict risk for onset of type 2 diabetes was ascertained from physiology data. 9\% of African Americans were in the at-risk category. All other participants were in normal range 1.0 for men and .8 for women and therefore not in the at-risk category for type 2 diabetes.

\section{Education}

Africans had more graduate school experience than the African American students in the study because more graduate students responded to participate among the African groups. More undergraduates responded among African Americans (Table 1). Both African and African American parents had some college, African parents had more exposure to college than African American parents did. In Principle Component Analysis, parents' education drove the education of the participants. The education of the parents accounted for $51 \%$ of the variation of the education category. Also the parents' education was found to be a highly significant driver of parents' income $(\mathrm{P}=<.0001)$ in the category of socio-economic status. African American parents therefore may be at risk for chronic stress increases in cortisol levels and BMI among populations without a college degree (Daniel et al., 2006).

\section{Exercise}

Both Africans and African Americans were exercising for at least 1.5 hours a day. Africans were more likely to ride bikes and walk to school or work than African Americans. African Americans were more likely to drive to school or work than Africans. African Americans were from neighborhoods (Midwest, Chicago) where structural violence was an issue, an effect that results in residents of bad neighborhoods not being able to exercise (walking) outdoors (Lillioja et al., 1988). There was also an effect of poverty of place and disadvantaged community acting upon African American neighborhoods, where there are no health clubs access to fresh produce and where fast food outlets are plenteous (Spence et al., 2009; Black, 2008; Gregson, 2009; Ruel et al., 2010). African Americans were getting 30 minutes of exercise, they just were walking to other places besides school or work. "Walking vs. driving" and "driving to school or work" were found to be highly significant negative interactions in Principle Component Analysis .Physical activity may be able to help both groups diminish any additive effects, if they exist, of BMI heritability and waist circumference (Mustelin et al., 2009).

\section{Food Preferences}

Both African and African Americans admitted to being selfmotivated fast food consumers from outlets like McDonalds and Red Lobster. Both groups consumed steamed vegetables, fruit, water and low fat milk, deviating from their parental preference for whole milk.

African and African Americans had a common taste preference for chicken. When African Americans were asked to list "what their favorite foods were," what they didn't list was a strong preference for cultural soul food staples like collard greens and sweet potato pie. This could represent an equistance from cultural preferences in foods, either attributable to the fact the parents of the African American participants aren't preparing foods like their parents did, or the fact that the taste preferences of African American youth are becoming less cultural and more assimilationist.

Both Africans and African Americans were found to be at risk for poor health associated with fast food consumption (Satia, 2004). The parents of both groups modeled good nutritional influence before them with regards to milk consumption (Arcan, 2007). African Americans may be reflecting the modeling of their parents' poor behavior of high fat consumption though their consumption of fast food (Rossow, 1994). Africans may be demonstrating transition away from traditional diets towards Westernized eating habits and may be putting themselves at risk for obesity and obesity related diseases due to consumption of Americanized fast food (Astrup, 2008). Both groups may reflect the modeling of positive nutritional influences of facilitated consumption of fruit, vegetables and milk from their parents (Young, 2004). Both groups were participating in privileged behavior with regards to their preferences for low fat milk (Gregson, 2009).

\section{Food Preparation}

African and African Americans were cooking their own meals and were cooking like their parents. The preferences among African Americans to prepare their foods fried most often may reflect negative nutritional influences of their parents in the home (Rossow, 1994).

Although the African participants may have had more positive nutritional modeling from their parents, they were not pre- 
serving these parents' cooking methods at a faster rate than African Americans, thereby opening the possibly of the gain of poorer and unhealthy habits (Satia, 2004). The fact that both groups like to try new recipes, may facilitate the acquisition of new preferences, independent of parental cultural methods that may not be unhealthier (Larson, 2006).

African Americans liked fried meats more than Africans but Africans liked frying their chicken more than African Americans, who preferred baking it. In cooking their foods African Americans preferred to first use the frying pan, then the microwave; for their meat. They preferred frying primarily and then grilling, and chose to bake their chicken. Africans preferred to grill and then slow cook their meats and to use baking and microwaving to prepare the food in general and a rice cooker. It was problematic that both groups used the microwave to prepare their foods because this exposes each to plastics and heat and the possibility of exposure to BPA and its effects (vom Saal, 2005). Both groups on average took at least an hour to prepare their meals.

Therefore, in preparing their own meals both African and African Americans were participating in better diet quality (Larson, 2006). The preferences for fried foods among African Americans could lead to obesity in Black men (Weinrich et al., 2007).

\section{Gardening}

Neither group gardened.

\section{Geography}

This research study did not assume that cultures were static. A person born in one place may not have been raised in another. Among Africans participants who could have been of West African heritage, they could have moved within the continent of Africa, the same is true for African Americans within the U.S. Principle Component Analysis of the category of Geography correlates placement of "tribes" with "region" and "country $(\mathrm{P}=<.0001)$."

The main country of influence among African participants was Nigeria with regional birthplaces in West and South Africa. The main tribes represented in the study were Yoruba and Shona. African Americans were more staticly influenced by the USA with regional birthplaces of the Midwest and South. Both groups were born in urban settings.

African mothers were from Nigeria, Zimbabwe and Ethiopia and represented the East and South African regions and the Shona and Yoruba tribes. African American mothers were from the Midwest, USA. African fathers were born in Nigeria, Ethopia, Zimbabwe and Ghana, represented the West, South and East regions and the Yoruba and Shona Tribe. African American fathers were born in the Midwest and Southern USA. Both African and African American parents were from urban regions (even though African American parents listed rural as "region of exposure," they are from the Midwest which is an entirely rural setting even for residents of Chicago. Neither African nor African American parents were exposed to farms.
Maternal African grandmothers were born in Nigeria, represented the West and South African regions and were of the Yoruba and Shona tribes. African American grandmothers were from Midwestern and Southern USA. Maternal African grandfathers were born in Nigeria, Ethiopia, Zimbabwe and Ghana, represented the West, South and East African regions and were of the Yoruba, Shona and Ewe tribes. African American grandfathers were from the USA.

Paternal African grandmothers were from Nigeria, represented the West, South and East African regions and were of the Shona and Yoruba tribes. Paternal African grandfathers were from Nigeria, Zimbabwe and Ethiopia, represented the West, East and South African regions and were of the Yoruba, Shona and Akan tribes. African American paternal grandmothers were from Southern and Midwestern USA. Paternal African American grandfathers were from USA representing the Southern and the Midwestern regions.

\section{Height}

Africans were slightly taller and leaner than their African American counterparts. This may be attributable to geographic location of origin in proximity to the equator that influences taller leaner phenotypes due to warm climate.

\section{Meal Planning}

Both Africans and African American groups like to grocery shop, took the time to plan meals, liked to try new recipes and make grocery lists. Africans had a stronger tendency to try new recipes and plan meals than African Americans and this may explain why this group is not preparing meals like their parents at a faster rate than African Americans. Meal planning has the potential to improve self-efficacy among both groups and have a favorable impact on consumption and better diet quality (Young, 2004; Larson, 2006).

\section{Obesity}

Obesity encompasses four categories: heritability, cultural consumption, future prevalence and a combination of the three. $18 \%$ of African Americans compared to $10 \%$ of African parents were reported to be overweight, therefore the heritability component of BMI (Ludwig et al., 2001) isn't strongly supported in the data. But the nutritional beliefs of both African and African American parents to feed their children sweetened drinks in childhood, could have had implications on control of calorie consumption during the slow growth period prior to adolescence, this combined with the obeseogenic side effect of sugar (Nissinen et al., 2009) could have contributed to the presence of fat cell formation in adults today (Spence \& et al., 2009). And the fact that both groups were heavy consumers of meat, soda, Koolaid, liked sweets and fast foods; could result in a future tendency towards obesity (Ludwig et al., 2001; Goran et al., 2012; Astrup, 2008; Satia, 2004; Befort, 2006). Additionally, in African Americans the tendency of their parents to model fast food consumption, the lessened tendency towards sit down meals and 
the fact that their parents did not breast fed them in considerable numbers, eliminating obesity prevention benefits of breast feeding, and exposure to the endocrine disruptor BPA through plastic baby bottles, infant formula, plastics, microwaving and consumption of fruits and vegetables through cans-could put them more at risk than Africans of obesity (Rossow, 1994; Anderson and Blackburn, 2008; Martorell et al., 2001; vom Saal, 2005).

Though the majority of both groups did not self report as overweight, there were responses that were given that could set the stage for overweight. In Multiple Regression Analysis "whether the participant were breast or bottle-fed"; "ate fried foods"; the "frequency of fried food consumption;", the tendency to have family sit down meals"; "whether one was raised eating fried foods;" "were overweight as a child;" "liked soda" and "how often they drank it;" "whether participants ate while watching television"; "time spent in the U.S.;" and "whether or not they drank water"-were all highly significant to fat percentage $(\mathrm{P}=<.0001)$. Whether participants "described themselves as overweight" and "time spent in the U.S." were highly significant interactions in Principal Component Analysis $(\mathrm{P}=<.0001)$. "Overweight in childhood" and "self description of overweight" or "normal weight"; "self description of overweight" and "body fat percentage;" "normal weight" description and "body fat percentage;" "normal weight" description and "age;" "BMI" and "body fat percentage"; "self description of overweight;" and "body fat percentage" and "weight" were all highly correlated interaction in Principle Component Analysis $(\mathrm{P}=<.0001)$ (Table 1$)$.

\section{Parental Preferences}

The contribution of parental preferences was both positive and negative. The parents of both groups modeled and facilitated consumption of fruit, vegetables and milk in the home (Nanney, 2007; Tibbs, 2001; Young, 2004; Arcan, 2007). Principle Component Analysis (Table 1) confirmed that parents were "eating vegetables" and "drinking milk;" parents "eating fruit" and "eating vegetables" and parents "eating fruit" and "drinking milk"-were all highly significant interactions $(\mathrm{P}=<.0001)$. The tendency to impact good nutrition at mealtimes and the practice of family sit down meals was stronger in Africans than African Americans (Utter, 2008). Yet, both parents held the consumption of sweetened drinks in their nutritional belief system and fed this to their children thereby putting them at risk for adult obesity (Anderson et al., 2009; Anderson and Blackburn, 2008; Ludwig et al., 2001). And African American parents modeled fast food consumption to their children, increasing their likelihood for high fat consumption in adulthood (Rossow, 1994).

\section{SES}

The "socio-economic status of the parents or SES," was correlated with their "education" in Principle Component Anaylsis $(\mathrm{P}=<.0001)$ (Table 1). African parents were slightly more affluent than African American and had more college exposure. African American parents were more at risk for chronic stress increases to cortisol levels and BMI among populations w/o a college degree (Daniel et al., 2006) and poor food choice due to income (Turrell, 2003).

\section{Time in the US}

"Time spent in the U.S." was highly correlated with "body fat percentage" and "weight" in Multiple Regression Analysis $(\mathrm{P}=<.0001)$ (Table 2). The longer participants stayed in the U.S. the more likely their tendency to increase body fat percentage. Time spent in the U.S. for Africans varied between 4 months and 33 yrs. African Americans were in the U.S. all their lives and had a higher tendency to be affected by increase in body fat percentage than Africans, yet both groups are in this risk category.

\section{Conclusions}

Fruit, vegetables and meat were generally affordable and available to all groups. There were subgroups within each that couldn't afford these items (Table 1). The indication here was that if meat were free, these groups would over consume this product, therefore the removal of cost as a barrier to meat consumption may lead to overconsumption. Both groups had fruit, vegetables and meat in their kitchen in some form. However, African Americans derived their fruits and vegetables from cans and frozen, which presents another factor of food exposure to an undesirable chemical in preservatives, such as BPA.

Africans and African Americans were found to be of a generation that grew up in the U.S. under plastics and microwaving. Microwaving was a preferred method of cooking for African Americans vs. Africans. African Americans were found to derive almost all of their vegetables and fruits from cans and they liked vegetables heated from cans. Both groups fell within income groups with high mean BPA concentrations according to Lang et al. (2008). Exposure to Bisphenol A (BPA) from plastic baby bottles as babies from formula (Consumers Union, 1995; Cao, 2008; Newbold, 2007) and may have been at risk of underdevelopment of their metabolic systems as babies (Janssen S. in Kotz, 2008). Therefore, African Americans were found to be at great risk for the effects of BPA.

The study revealed that "cultural influences" played an important role in food preferences (Tables 1 and 2).

Both groups liked to eat fast food and attributed their love of fast food to themselves. African Americans were more likely though to have exposure to fast foods in their childhood than Africans. The parents of African Americans raised them eating fast foods, while the parents of Africans raised their children on home cooked meals. Thus, all groups were at risk of fat consumption from fast food outlets, in agreement with earlier studies (Befort, 2006). With respect to beverages, Africans and African Americans were neutral in their preferences for milk and they deviated from their parents' preference for whole milk by preferring low fat milk; they both liked sweet tea, soda, Koolaid and water. Sweetened drinks were a part of the nutritional belief system of both African and African American parents and they facilitated consumption to their children accordingly. Physical 
activity may be able to help both groups diminish any additive effects, if they exist, of BMI heritability and waist circumference (Mustein, 2009). This study showed that both Africans and African Americans were exercising for at least 1.5 hours a day. Africans tended to ride bikes and walk to school or work than African Americans (Tables 1 and 2).

Both Africans and African Americans were found to be at risk for obesity and type 2 diabetes due to exposure of high fructose corn syrup (HCFS) in soda (Goran et al., 2012). Examination of the relationship between responses to the questions of " if type 2 diabetes ran in the participants" family" and "if the participants themselves reported a diagnosis of type 2 diabetes?" The diagnosis of "type 2 diabetes" among participants accounted for $52 \%$ of the variation of the diabetes, affected category. The majority of the participants did not report a diagnosis of "type 2 diabetes." A regional pattern of fat distribution used to predict risk for onset of type 2 diabetes was ascertained from physiology data (Johnson, 2019). 9\% of African Americans were in the at-risk category. All other participants were in normal range 1.0 for men and .8 for women, and therefore not in the at-risk category for type 2 diabetes. Obesity encompassed four categories: heritability, cultural consumption, future prevalence and a combination of the three. More African Americans were reported to be overweight than Africans. Therefore, the heritability component of BMI (Ludwig, 2001) was not supported in the data.

- There are different correlates and determinants of BMI and diabetes in African Americans than European AmericansSome aspects differ between American-born and African-born African Americans

- There exists barriers on the level of community affecting African Americans.

- The food environment in the U.S. has changed from agrarian to convenience to fast foods and now GMOs. Our food supply is toxic and the public is unprotected from the effects of GMOs and growth hormones

- Diabetes will continue to effect AA's in response to historical pressures of the past and additive pressures of subjugation pressure and poverty.

Note: Proximity to produce does not necessarily impact consumption of produce in populations where healthier food consumption like produce and water are not a part of their nutritional beliefs or has been a part of parental modeling. The success of efforts to increase consumption of healthier foods may benefit from a protocol of facilitated consumption, like food preparation guidance and creative campaigns that encourage consumption; foods being made affordable and convenient to nutritionally poor groups.

\section{References}

Alaimo K., CM Olson, EA Frongillo Jr, and RR Briefel (2001) Food Insufficiency, Family Income \& Health in U.S. Preschool \& School-Aged Children. Amer J Clin Nutr 91(5): 781-786.

Anderson CM, and EH Blackburn (2008) Mec1 Function in the DNA Damage Response Does Not Require its Interaction with Tel2. Cell Cycle 7 (23): 3695-3698.

Arcan, C., D Neumark-Sztainer, P Hannan, P Van Den Berg, M Story, and N Larson (2007) Parental Eating Behaviors, Home Food Environment and Adolescent Intakes of Fruits, Vegetables and Dairy Foods; Longitudinal Findings from Project EAT. Pub Hlth Nutr 10 (11): 1257-1265.

Astrup A, J Dyerberg, M Sellect, and S Stender (2008) Nutrition Transition and its Relationship to the Development of Obesity and Related Chronic Diseases. Obes Rev 9 (Suppl 1): 48-52.

Bandura A (1989) Social Cognitive Theory. In R. Vasta (Ed.) Ann. Child Dev 6: pp. 1-60. Greenwich: Jai Press.

Befort C, H Kaur, N Nollen, DK Sullivan, N Nasir, WS Choi, L Hornberger, and JS Ahluwalia (2006) Fruit, Vegetable and Fat Intake among Non-Hispanic Black and Non-Hispanic White Adolescents; Associations with Home Availability and Food Consumption Settings. J Amer Diet Assoc 106 (3): 367-373.

Black J (2008) Assessing the Neighborhood-Level Determinants of Obesity in New York City. (Doct Diss, New York University, Graduate School of Arts and Science).

Bronfrenbrenner U. (1989). Ecological Systems Theory. In Vasta (ed.), Ann. Child Dev. Vol. 6, pp. 187-249). Greenwich: JAI Press.

Brotons JA, MF Olea-Serrano, M Villalobos, V Pedraza,and N Olea (1995) Xenoestrogens Released from Lacquer Coating in Food Cans. Environ Hlth Perspect 103 (6): 608-612.

Cao XL, and J Corriveau (2008) Migration of Bisphenol a from Polycarbonate Baby and Water Bottles into Water under Severe Conditions. J Agr \& Food Chem 56 ( 5): 6378-6381.

Cassady D, KM Jetter, and Culp, J (2007) Is Price a Barrier to Eating More Fruits \& Vegetables for Low Income Familes? J Amer Diet Assoc 107 (11): 1909-1915.

Cotterchio M., BA Boucher, M Manno, S Gallinger, AB Okey, and PA Harper (2008) Red Meat Intake, Doneness, Polymorphisms in Genes that Encode Carcinogen-Metabolizing Enzymes, and Colorectal Cancer Risk. Cancer Epidem Biom Prev 17 (11): 3098-3107.

Daniel M, DS Moore, S Decker, L Belton,B DeVellis, A Doolen, and MK Campbell (2006) Associations among Education, Cortisol Rhythm, and BMI in Blue-Collar Women. Obes. 14 (2): 327-335.

Devine CM, EA Frongillo, and CA Bisogni (1999) Life-Course Events and Experiences: Association with Fruit and Vegetable Consumption in 3 Ethnic Groups. J Amer Diet Assoc 99 (3): 309-314.

Evans EM, DA Rowe, SB Racette, KM Ross, and E McAuley(2006). Is the Current BMI Obesity Classification Appropriate for Black and White Post-Menopausal Women? J Obes 30 (5): 837-843.

Giovannucci E, EB Rimm, MJ Stampfer, GA Colditz, A Ascherio, and WC Willett (1994) Intake of Fat, Meat, and Fiber in Relation to Risk of Colon Cancer in Men. Cancer Res 54 (9): 2390-2397.

Goran MI, SJ Ulijazek, and EE Ventura (2012) High Fructose Corn Syrup and Diabetes Prevalence: A Global Perspective. Glob Pub Hlth 8 (1): 55-64. 
Gregson J (2009) How Inequality Influences Individuals Through the Built Food Environment. PhD, University of California, Davis. Proquest Diss \& Theses database.

Howdeshell KL, AK Hotchkiss, KA Thayer, JG Vandenbergh, and FS Vom Saal (1999) Environmental Toxins:Exposure to Bisphenol A Advances Puberty. Nature 401 (6755): 763764.

Hyoung, UJ, YJ Yang, SK Kwon, JH Yoo, SC Myoung, SC Kim, and YP Hong (2007) Developmental Toxicity by Exposure to Bisphenol A Diglycid Ether during Gestation and Lactation Period in Sprague-Dawley Male Rats. J Prev Med Pub Hlth 40 (2): 155-161.

Jetter KM and DL Cassady (2006) The Availability and Cost of Healthier Food Alternatives. Amer J Prev Med 30 (1): 3844.

Johnson C, R Corruccini; D Becque, W Moon, and DA Lightfoot (2019) A Culturally Competent Phenotypic Evaluation/ Obesity Assessment in African and African,American Populations: Pilot Study. Atlas J Bio. In Press.

Kennedy AP, JL Shea, and G Sun (2009) Comparison of the Classification of Obesity by BMI vs Dual-Energy X-Ray Absorptiometry in the New Foundland Population. Obes 17 (11): 2094-2099.

Kok P, JC Seidell, and AE Meinders (2004) The Value and Limitations of the Body Mass Index (BMI) in the Assessment of the Health Risks of Overweight and Obesity. Ned Tijdt voor Genees 148 (48): 2379-2382.

Komlos J, A Breitfelder, and M Sunder (2009) The Transition to Post-Industrial BMI Values among U.S. Children. Amer J Hum Bio, 21(2), 151-160.

Kotz D (2008) Anxieties in a Bottle (or a Can). U.S. News \& World Reports, 145.

Kremers SP, J Brug, H de Vries, and RC Engels (2003). Parenting Style and Adolescent Fruit Consumption. Appetite 41 (1): 43-50.

Lang IA, TS Galloway, A Scarlett, WE Henley, M Depledge, RB Wallace, and D Melzer (2008) Association of Urinary Bisphenol A Concentrations with Medical Disorders and Laboratory Abnormalities in Adults. JAMA 300 (11): 1303 1310.

Larson NI, C Perry, M Story, D Newmark-Sztainer (2006) Food Preparation by Young Adults is Associated with Better Diet Quality. J Amer Diet Assoc, 106 (12): 2001-2007.

Lillioja S, DM Mott, BV Howard, PH Bennett, H Yki-Järvinen, D Freymond, BL Nyomba, F Zurlo, B Swinburn, and C Bogardus (1988). Impaired Glucose Tolerance as a Disorder of Insulin Action. N Eng J Med 318 (19): 1217-1225.

Ludwig D S, Peterson KE, and SL Gortmaker (2001) Relation Between Consumption of Sugar-Sweetened Drinks \& Childhood Obesity: a Prospective Observational Analysis. Lancet 357: 505-508.

Lupien SJ, S King, MJ Meaney, and BS McEwen (2000) Child's Stress Hormone Levels Correlate w/Mother's Socioeconomic Status and Depressive State. Bio Psych 48 (10): 976-980.

Martorell R, AD Stein, and DG Schroeder (2001) Early Nutrition and Later Adiposity. J Nutr 131 (3): 874S-880S.
Mills TC, D Gallagher, J Wang, and S Heshka (2007) Modeling the Relationship Between

J Body Comp 5 (2): 73-79.

Moreland K, S Filomena (2007) Disparities in the Availability of Fruits \& Vegetables Between Racially Segregated Urban Neighborhoods. Pub Hlth Nutr 10 (12): 1481-1489.

Mustelin L, K Silventoinen, K Pietiläinen, A Rissanen, and J Kaprio (2009) Physical Activity Reduces the Influence of Genetic Effects on BMI and Waist Circumference: A Study in Young Adult Twins. Int J Obes 33 (1): 29-36.

Nanney MS, S Johnson, M Elliot, and D Haire-Joshu (2007) Frequency of Eating Homegrown Produce is Associated with Higher Intake among Parents and their Preschool-Aged Children in Rural Missouri. J Amer Diet Assoc 107 (4): 577 584.

Newbold RR, E Padilla-Banks, RJ Snyder,TM Phillips, \& WN Jefferson (2007) Developmental Exposure to Endocrine Disruptors and the Obesity Epidemic. Reprod Toxicol 23 (3): 290-296.

Nissinen K, V Mikkilä, S Männistö, M Lahti-Koski, L Räsänen, J Viikari, \& OT Raitakari (2009) Sweets and Sugar Sweetened Soft Drink Intake in Childhood in Relation to Adult BMI and Overweight. Pub Hlth Nut 12 (11): 2018-2026.

Nord M, M Andrews, and J Winicki (2002) Frequency \& Duration of Food Insecurity \& Hunger in U.S. Households. J Nutr Educ \& Behav 34 (4): 194-201.

Poole A, PV Herwijnen, H Weidli, MC Thomas, G Ransbotyn, and C Vance (2004). Food Add Contam, 21 (9): 905-919.

Rossow I, J Rise (1994). Concordance of Parental and Adolescent Health Behaviors. Soc Sci Med 38 (9): 1299-1305.

Ruel E, E Reither, S Robert, and P Lantz. (2010). Neighborhood Effects on BMI Trends: Examining BMI Trajectories for Black \& White Women. Hlth \& P1 16 (2): 191-198.

Satia JA, J Galanko, and AM Siega-Rix (2004) Eating at Fast Food Resturants is Associated with Dietary, Demographic, Psychosocial and Behavioral Factors among African Americans in North Carolina. Pub Hlth Nutr 7 (8): 1089-1096.

Satija A, SN Bhupathiraju, EB Rimm, D Spiegelman, SE. Chiuve, L Borgi, WC Willett, JE Manson, Q Sun, and FB Hu (2016) Plant-Based Dietary Patterns and Incidence of Type 2 Diabetes in US Men and Women: Results from Three Prospective Cohort Studies. PLoS. 13(6) e1002039.

Sharma S and SJ OKeefe (2007) Environmental Influences on the High Mortality from Colorectal Cancer in African Americans. Postgrad Med J 83 (983): 583-589.

Smalley KJ, AN Knerr,ZV Kendrick, JA Colliver, and OE Owen (1990). Reassessment of Body Mass Indices. Am J Clin Nutr 52 (3): 405-408.

Spalding KL, E Arner, PO Westermark, S Bernard, BA Buchholz, O Bergmann, LBlomqvist, J Hoffstedt, E Näslund, and T Britton (2008) Dynamics of Fat Cell Turnover in Humans. Nat. 453 (7196): 783-787.

Spence JC, N Cutumisu, J Edwards, KD Raine \& K SmoyerTomic (2009) Relation between Local Food Environments and Obesity among Adults. BMC Pub Hlth 9 (1): 192.

Stender S, J Dyerberg, and A Astrup (2007) Fast Food: Unfriendly \& Unhealthy. Int J Obes (London) 31 (6): 887 - 
890.

Takeuchi T, O Tsutsumi, Y Ikezuki, Y Takai, and Y Taketani (2004) Positive Relationship between Androgen and the Endrocrine Disruptor, Bisphenol A, in Normal Women and Women with Ovarian Dysfunction. Endocr J 51: 165-169.

Tang D, JJ Liu, A Rundle, C Neslund-Dudas, AT. Savera, CH Bock, NL Nock, JJ Yang, and BA Rybicki (2007) Grilled Meat Consumption \& PhIP-DNA Adducts in Prostate Carcinogenesis. Cancer Epidem Prev Biom 16 (4): 803-808.

Tibbs T, D Haire-Joshu., KB Schechtam, RC Brownson, MS Nanney, C Houston, and W Auslander (2001) The Relationship between Parental Modeling, Eating Patterns, and Dietary Intake among African American Parents. J Amer Diet Assoc 101 (5): 535-541.

Turrell G, B Hewitt, C Patterson, and B Oldenburg (2003) Measuring Socio-Economic Position in Dietary Research: is Choice of Socioeconomic Indicator Important? Pub Hlth Nutr 6 (2): 191-200.

Union C (1999). Baby Alert: New Findings about Plastics. Consum Rep, 28-29.

Utter J, R Scragg, D Schaaf, and CN Mhurchu (2008) Relationships between Frequency of Family Meals, BMI and Nutritional Aspects of the Home Food Environment among New Zealand Adolescents. Internl J Behav Nutr \& Phys Act, Oct; 23, pp. 5-50.

Van der Horst K., S Kremers, I Ferreira., A Singh, A Oenema, and J Brug (2006) Perceived Parenting Style \& Practices \& the Consumption of Sugar Sweetened Beverages by Adolescents. Hlth Educ Res 22 (2): 295-304.
Vom Saal FS, C Hughes (2005). An Extensive New Literature Concerning Low-Dose Effects of Bisphenol A Shows the Need of a New Risk Assessment. Environ Hlth Perspec 113 (8): 926-933.

Vygotsky L (1993) The Collected Works of L.S. Vygotsky (J. K. Stevens \& C, Trans.). New York: Plenum.

Wagner D and V Heyward (2000) Measures of Body Composition in Blacks and Whites: A Comparative Review. Amer. J Clin Nutr.71: 1392-1402.

Wardle J, S Carnell, and L Cooke (2005) Parental Control over Feeding \& Children's Fruit \& Vegetable Intake:How are they related? J Amer Diet Assoc 105 (2): 227-232.

Weinrich SP, J Priest, W Reynolds, PA Godley, W Tuckson, and M Weinrich (2007) Body Mass Index \& Intake of Selected Foods in African American Men. Publ Hlth Nurs 24 (3): 217 229.

Welshons WV, SC Nagel, and FS Vom Saal (2006) Large Effects from Small Exposures III Endocrine Mechanisms Mediating Effects of Bisphenol A at Levels of Human Exposure. Endoc 147 (6 Suppl): S56-69.

Young EM, SW Fors, and DM Hayes (2004) Associations between Perceived Parent Behaviors and Middle School Student Fruit and Vegetable Consumption. J Nutr Educ Behav 36 (1): 2-8.

Zenk SN, AJ Schulz, BA Israel, SA James, S Bao, and ML Wilson (2005) Neighborhood Racial Composition, Neighborhood Poverty, and the Spatial Accessibilty of Supermarkets in Metropolitan Detroit. Amer J Pub Hlth 95 (4): 660-667. 